\title{
The Effect of Mergers and Acquisitions in the Entertainment and Media Industry
}

\author{
Namgon Kim1), Jee-Hyun Kim²)
}

\begin{abstract}
The entertainment and media (E\&M) industry, one of the fastest growing sectors, is facing fierce competition worldwide as mergers and acquisitions (M\&A) have emerged as an important industry growth strategy. This paper aims to show whether M\&A events in the E\&M industry increase the shareholders' wealth. It investigates the stock price responses to the M\&A announcements and, furthermore, examines firm factors influencing the responses. For the analysis, the event study methodology was applied, using M\&A events in the Korean E\&M industry from 2000 to 2019. The test results reveal that, in the E\&M industry, shareholder value of acquiring firms earn about 0.08 cumulative abnormal returns (CAR) over 20 days until the announcement date and 0.04 average abnormal return (AAR) on the announcement date. The firms with high debt ratio are associated with lower CAR, while firm size does not exhibit any influence. The results indicate that M\&A announcements in the E\&M industry have a positive impact on stock prices and, thus, benefit shareholder wealth of the acquiring firms.
\end{abstract}

Keywords: Mergers and Acquisitions (M\&A), Entertainment and Media (E\&M) Industry, Wealth Effect, Abnormal Returns, Event Study

\section{Introduction}

The entertainment and media (hereafter referred also as E\&M) industry in South Korea has experienced a rapid growth since the 2000s. With the success of the Korean Wave (called Hallyu in Korean), a term for the Korean culture fad including K-pop and K-drama, the E\&M sector in South Korea has expanded its influence in Asia beyond the local country economy. After evolving into the Hallyu 2.0 era after late 2007 as a result of the development of mobile technology and social network services, the industry is now facing the Hallyu 3.0 era, with highly advanced digital technologies serving as a driving engine.

Received(April 17, 2020), Review Result(1st: June 2, 2020, 2nd: July 29, 2020), Accepted(August 28, 2020)

1) (Professor) 02748 Dept. Business Administration, Dongduk Women's Univ., Wolgok-dong, Sungbuk-gu, Seoul, Korea

email: fencer@dongduk.ac.kr

2) (Associate Professor, Corresponding Author) 24252 Finance Dept., Hallym Univ., Chuncheon-si, Gangwon-do, Korea

email: jhyunkim@hallym.ac.kr 
With the rapid development of high technologies, such as Artificial intelligence (AI), the world economy is experiencing the 4th industrial revolution, which will influence every aspect of human life and business organizations[1-4]. The E\&M industry is not an exception. In a drastically changing environment, mergers and acquisitions (hereafter referred to as M\&A) have become one of the crucial survival strategies among E\&M firms.

A merger typically refers to a full combination of two companies into one organization, while an acquisition occurs when one company purchases another company but the legal independence of acquired company remains. Due to synergy effects from combination, the M\&A market has substantially increased over the last two decades. Since 2000, more than 790,000 M\&A deals have been disclosed globally with a value of about 57 trillion dollars. In the E\&M industry, two entertainment giants, Marvel entertainment and Walt Disney, agreed on an M\&A deal in 2009, which was the year's biggest media deal. Another significant M\&A deal, worth of $\$ 52.4$ billion, was announced in 2017 by Walt Disney and 21st Century Fox.

[Fig. 1] shows M\&A statistics in terms of number and value. When comparing panels $A$ and $\mathrm{B}$, a more profound increase of M\&A transactions is observed in the Asia-Pacific region. The number of M\&As in the Asia-Pacific region soared from 5,951 in 2002 to 15,772 in 2019, while it increased less than twice worldwide from 27,201 to 49,849 . The total value in the Asia-Pacific region reveals a nearly sixfold increase (from $\$ 153.01$ billion in 2002 to $\$ 877.69$ billion in 2019), while it shows about a threefold increase (from $\$ 1,242$ billion to $\$ 3701.44$ billion) worldwide.

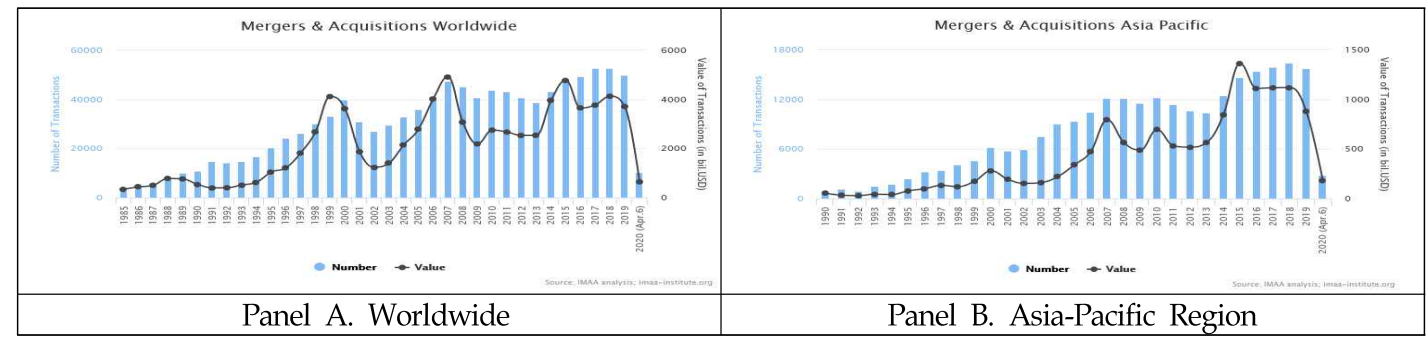

[Fig. 1] Mergers and Acquisitions (Source: IMAA analysis, imaa-institute.org)

Prior studies investigating the M\&A effects on the shareholders' wealth of a bidding firm have been unsuccessful in arriving at a unified result, while their efforts provide quite consistent evidence for those of a target firm. For example, Martynova and Renneboog[5] and Craninckx and Huyghebaert[6] show that target firms can obtain significantly positive stock returns around the $M \& A$ announcement date and, therefore, the shareholders can benefit from the M\&A deals. However, with regard to bidding firms, while some studies (e.g., Mateev[7], Danbolt and Maciver[8], and Mattev and Andonov[9]) report a positive influence of the M\&A 
announcement on its shareholders, another strand of the literature (e.g., Isa and Lee[10]) argues a negative effect of the event on shareholders by presenting negative stock returns around the M\&A announcement date.

Most previous studies are limited because they ignore industry-specific features and analyze samples of heterogeneous industries. Despite the current and still-increasing importance of the E\&M industry in the economy, scarce research has investigated the effects of financial decisions in this industry from a financial perspective.

This paper has two objectives. The primary objective is to examine the behavior of stock price around M\&A announcements of acquiring firms. The second objective is to investigate whether firm factors known for having influence on the magnitude of stock returns around M\&A announcements still play a role in M\&As by the E\&M companies. This paper adopts an event study methodology using samples of M\&A events collected from the South Korean E\&M industry between 2000 and 2019. In particular, it measures excess returns and cumulative excess returns and evaluates whether M\&A events contribute the shareholders' wealth of acquiring firms. Furthermore, this article examines the effect of firm characteristic factors on stock price responses in the E\&M industry by conducting multivariate regression analysis. With the lack of academic research exploring this topic with industry context, we expect this research to provide valuable insight into understanding the effects of financial decisions in the E\&M industry and the possible differences from market-wide research results for influencing stock returns. In line with an enhanced understanding, this study may contribute to the decision-making process for various financial market participants, including current and potential shareholders, firms' financial managers, and policy makers.

The rest of this paper is structured as follows. The following section presents literature related to M\&As and the E\&M industry. Subsequently, in Section 3, we briefly describe the E\&M market in South Korea and introduce major recent M\&As. Section 4 provides empirical results. Finally, the paper is concluded in Section 5.

\section{Literature Review}

\subsection{Literature on the M\&A Announcement Effect}

Since M\&As are considered as effective survival and growth strategies, numerous researchers have investigated its impact. Previous empirical studies concerned with M\&As value creation surrounding public announcement present clear evidence about target firm shareholder value. 
Most studies arrive at the conclusion that the M\&A activities increase the value of a target firm's shareholders. Among recent papers, Martynova and Renneboog[5] show that UK target companies generate positive returns that are higher than Continental European counterparts in both domestic and cross-border M\&A transactions. Craninckx and Huyghebaert[6] also report positive abnormal returns for target firms' shareholders. When comparing the magnitude of benefits between targets purchased by UK or Irish firms versus Continental European firms, they found larger benefits for firms targeted by the former firms.

However, findings are less certain with respect to bidding firms. Craninckx and Huyghebaert [6] argue that bidding firms in Continental Europe enjoy positive abnormal returns, whereas those in the UK or Ireland experience a negative stock reaction of $-0.83 \%$. Mateev[7] concludes that shareholders of acquiring firms benefit from integration regardless of location. These findings are in line with the results of Danbolt and Maciver[8] and Mattev and Andonov [9]. Analyzing the Malaysian market, Isa and Lee[10] report positive stock price reactions of bidders on day 0 and day 1. Analyzing the US market from a period of 2009 to 2012, Stunda[11] found significantly negative effects on stock prices of the acquiring firms.

These inconclusive results lead us to re-examine the influence of M\&As on acquiring firms and their shareholder value with a more specified sample.

\subsection{Literature on the E\&M Industry}

Chae and Yoon[12] study the strategies for K-pop in France, where there exists a new market for the Korean Wave. After interviewing French experts, they find spill-over effects from K-pop in other areas. Cho and Sim[13] seek to find key ingredients for K-pop's success. They suggest that efficient infrastructure for content producers, network providers, platform subscribers, and terminal enterprises is crucial for a sustainable Korean Wave. Kwon and Kim[14] investigate the Korean government's endeavor to promote the Korean cultural industries. In the early 1990s, the government shifted its strategy from political control to viewing them as exportation items. In the 2000s, along with the conjunction of living standards improvements and information and communication technologies (ICT), Korean cultural industries, such as K-pop, have increased their influence in the global markets. Fedorenko[15] examines conflicts stemming from the trans-nationalization of Korean celebrities. Presenting different demands from domestic and international observers, the author argues that Hallyu stars' apolitical neutrality raises their global value. Parc and Moon[16] examine the success factors for competitiveness of Hallyu, focusing on Korean drama and film. Adopting a comprehensive analytical tool, they identify 
that the global popularity of Korean entertainment can be considered as a sustainable rather than a temporary phenomenon. These studies highlight the important position of the Korean E\&M industry in the global economy.

Yanga and Kim[17] investigate cross-border M\&As by Chinese E\&M companies, targeting either US or Korean companies. They also examine factors influencing the value added from those M\&A activities. Showing the changes in return on sales (ROS), return on assets (ROA), and return on equity (ROE), they argue that cross-border M\&As have negative influence on long-term performance. Jha[18] provides a framework that links cultural differences with M\&A performance through the psychological safety of employees from acquired firms.

Considering the growing importance of M\&As in the E\&M industry and the inconclusive results for bidding firms' shareholder value, surprisingly limited literature addresses this issue in the E\&M industry. In this paper, we seek to fill this gap by examining the stock price behavior of acquiring firms around the M\&A deals announced in the E\&M industry.

\section{The Entertainment and Media Industry Analysis}

\subsection{The Market Snapshot of the Entertainment and Media (E\&M) Industry in Korea}

The South Korean E\&M market has experienced strong growth over the last two decades. [Table 1] presents recent financial performance for four giant entertainment management companies in Korea: JYP, SM, YS, and BigHit Entertainments. Among these goliaths, BigHit showed the most radical growth between 2016 and 2018 and ranked first place in net profit. Its success is largely driven by the mega hit of BTS, an idol music group that debuted in 2013.

In 2018, BigHit accumulated 214.2 billion won (approximately US\$181.51 million) in revenue along with 64.1 billion won (US\$54.28 million) and 50.2 billion won (US\$42.51) in operating profit and net income, respectively. Compared to 2016, these numbers show more than sixfold increases in revenue, EBIT, and net income. SM Entertainment (SME), which has dominated the K-pop sector since 2000, earned about 612.2 billion won in revenue, nearly three times the amount BigHit Entertainment collected. Despite this outstanding revenue, however, net profit was unexpectedly low with less than half that of BigHit. [Fig. 2] compares revenue and EBIT between SME and BigHit. We can observe the radical growth of BigHit from 2016 to 2018. 
The Effect of Mergers and Acquisitions in the Entertainment and Media Industry

[Table 1] Major Entertainment Management Companies in the Korean E\&M Industry (unit: million won)

\begin{tabular}{|c|c|c|c|c|c|c|}
\hline Name & Year & Total Assets & $\begin{array}{c}\text { Total } \\
\text { Liabilities } \\
\end{array}$ & Revenue & EBIT & Net profit \\
\hline \multirow{3}{*}{$\begin{array}{c}\text { JYP } \\
\text { Entertainment }\end{array}$} & 2016 & 86,572 & 19,530 & 73,645 & 13,812 & 8,525 \\
\hline & 2017 & 124,428 & 38,668 & 102,242 & 19,463 & 16,369 \\
\hline & 2018 & 159,342 & 31,374 & 124,821 & 28,749 & 24,275 \\
\hline \multirow{3}{*}{$\begin{array}{l}\mathrm{SM} \\
\text { Entertainment }\end{array}$} & 2016 & 525,083 & 149,536 & 349,870 & 20,705 & 4,226 \\
\hline & 2017 & 797,509 & 361,878 & 365,387 & 10,941 & $-4,709$ \\
\hline & 2018 & $1,002,474$ & 426,346 & 612,227 & 47,746 & 23,420 \\
\hline \multirow{3}{*}{$\begin{array}{c}\text { YG } \\
\text { Entertainment }\end{array}$} & 2016 & 486,836 & 136,465 & 321,839 & 31,919 & 14,099 \\
\hline & 2017 & 583,600 & 151,495 & 349,861 & 24,158 & 11,911 \\
\hline & 2018 & 594,324 & 144,880 & 269,016 & 19,807 & 15,945 \\
\hline \multirow{3}{*}{$\begin{array}{l}\text { BigHit } \\
\text { Entertainment }\end{array}$} & 2016 & 16,939 & 3,472 & 35,220 & 10,380 & 9,008 \\
\hline & 2017 & 61,172 & 20,652 & 92,401 & 32,545 & 24,568 \\
\hline & 2018 & 149,715 & 58,304 & 214,221 & 64,136 & 50,233 \\
\hline
\end{tabular}

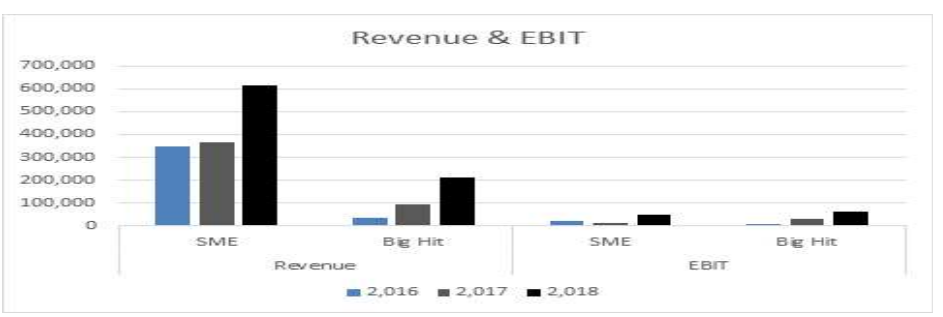

[Fig. 2] Revenue and EBIT: SME vs. BigHit (unit: million won)

\subsection{Examples of Recent Major M\&As in the Entertainment and Media Industry}

M\&A activities by major entertainment management companies seem very plausible in Korea. After starting with only one idol music group, BTS, BigHit has grown rapidly along with the popularity of BTS as global super stars. BigHit is now planning to take the next step for expansion. BigHit is known for seeking ways to widen revenue sources and pursuing M\&As as one viable strategy. On July 29th of 2019, BigHit was reported to be planning to conduct an M\&A deal with Source Music, a major entertainment company that manages popular female K-pop idol music groups.

SME has already completed several important M\&A deals. Recently, in 2018, it announced the purchases of KeyEast Entertainment and FNC Add Culture, prominent labels focusing largely on acting and media production, respectively. SME announced its plan to take a $25.12 \%$ stake in KeyEast, a company owned by the former popular Korean actor, Bae Yong-joon, at 50 billion won (approximately US\$47 million) in a deal split between cash and stock. It separately 
reported that it was acquiring $30.51 \%$ of FNC Add Culture stock at 30 billion won (approximately US\$28 million).

[Table 2] SME's Acquisition of KeyEast and FNC Add Culture

\begin{tabular}{|c|c|c|}
\hline & KeyEast & FNC Add Culture \\
\hline $\begin{array}{c}\text { Market } \\
\text { cap.(3/13/18) }\end{array}$ & 223.5 billion Korean won & 79.8 billion Korean won \\
\hline Stake acquisition & $25.12 \%$ & $30.51 \%$ \\
\hline Deal size & $\begin{array}{l}50 \text { billion Korean won (US\$46.88 } \\
\text { million) }\end{array}$ & 30 billion Korean won (US\$28 million) \\
\hline Details & $\begin{array}{l}\text { New share issue and purchase of } \\
\text { existing shares } \\
\text { 1) } 35 \text { billion Korean won in new SM } \\
\text { shares to be issued } \\
\text { 2) } 15 \text { billion Korean won in existing } \\
\text { KeyEast shares to be acquired }\end{array}$ & $\begin{array}{l}\text { Purchase of existing shares and equity } \\
\text { issue participation } \\
\text { 1) } 20 \text { billion Korean won in existing } \\
\text { shares to be acquired } \\
\text { 2) } 10 \text { billion Korean won in new } \\
\text { shares to be acquired }\end{array}$ \\
\hline $\begin{array}{l}\text { Purpose of } \\
\text { acquisition }\end{array}$ & $\begin{array}{l}\text { Support for digital and platform } \\
\text { business through enhanced } \\
\text { entertainment and contents (artists, } \\
\text { music, MCN, UGC, etc.) }\end{array}$ & $\begin{array}{c}\text { Synergies with SME in } \\
\text { drama/broadcasting production and } \\
\text { Global lifestyle businesses including } \\
\text { retail, F\&B, fashion, and leisure }\end{array}$ \\
\hline
\end{tabular}

\section{Empirical Results}

Our sample consists of M\&A announcements in the entertainment and media industry in Korea between January 2000 and December 2019. Most of the previous literature examined firm value around M\&A announcements using an event study methodology to assess abnormal return (AR) and cumulative abnormal return (CAR) of stock prices of target or acquiring firms.

For robustness, we adopted two event study methodologies, the capital asset pricing model (CAPM)-adjusted model and the market-adjusted model, using different benchmarks for the normal rate of return in Event Study 1 and Event Study 2, respectively. Abnormal return (AR) is obtained by subtracting a benchmark return from the realized stock return and cumulative abnormal return (CAR) can be obtained by adding abnormal returns to daily observations. The relevant formulae read as follows:

$A R_{i, t}=R_{i, t}-E\left(R_{i, t}\right)$, where $\mathrm{i}$ and $\mathrm{t}$ indicate firm $\mathrm{i}$ and day $\mathrm{t}$.

$$
C A R_{i, t 1, t 2}=\sum_{t=t 1}^{t 2} A R_{i, t}
$$

Average abnormal return (AAR) and cumulative average abnormal return (CAAR) can be obtained by calculating the averages of abnormal returns and cumulative abnormal returns 
across firms, respectively.

[Fig. 3] plots the AARs and CAARs over a period of 20 days from before an M\&A announcement to 10 days after. The CAPM-adjusted model and market-adjusted model are applied in Panel A and Panel B, respectively.

The graphs in Panel A reveal significantly positive AAR and CAAR on day 0 and day 1 . In addition, no return reversal in the CAARs is observed up to 10 days after the announcement. After day 1, CAARs decline some and then level off at a higher value than before the M\&A announcement. These results indicate that an increase of acquiring firms' shareholder wealth in the E\&M industry. Similar results are found in Panel B, where the event study using the market-adjusted model is utilized. The short and sharp increases of returns immediately after an announcement suggest stock prices overshoot as an initial response to the event.

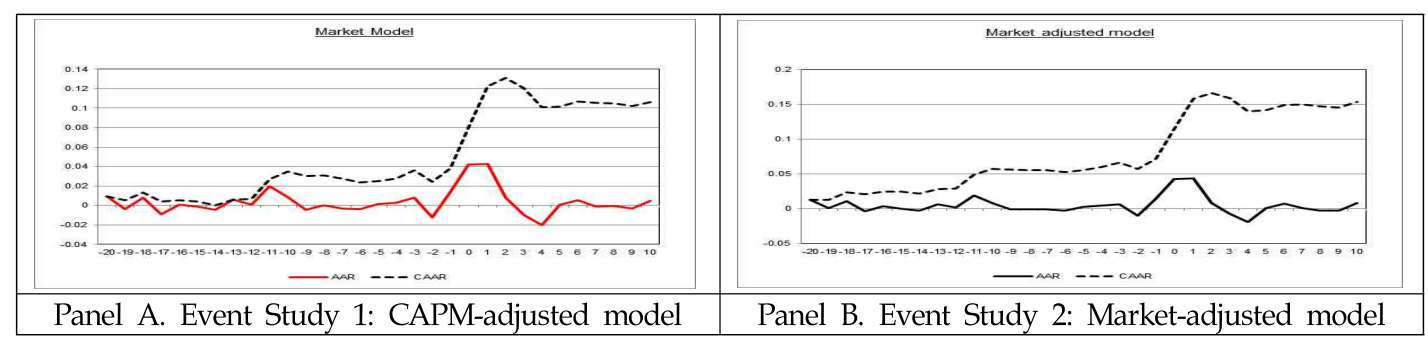

[Fig. 3] Stock Return Movements Around the M\&A Announcement: AAR and CAAR

[Table 3] provides observations of AAR and CAAR on a daily basis in detail. In Panel A where Event Study 1, we can see the average abnormal return on the announcement day (day 0 ) is about 0.042 with a $1 \%$ significance level. This result rejects the null hypothesis that there is no wealth effect from the information of an M\&A announcement. The results are in line with the findings of several previous studies (for example, Chakraborty[19]).

The CAARs decline from day 3 to day 5, indicating that the investors overreact during the first several days immediately following the announcement. The AARs show the largest reactions on day 0 and day 1 , with 0.042 and 0.043 , respectively. AARs drop rapidly, however, presenting even negative values on day 3 and day $4(-0.010,-0.020)$. After experiencing a sharp drop, AARs stay near zero and CAARs level off at around 0.10. Panel B, using the event study with the market-adjusted model, also presents similar results.

[Table 3] AAR \& CAAR around the M\&A Announcement

Panel A: Event Study 1 (CAPM-adjusted model)

\begin{tabular}{|c|c|c|c|c|}
\hline Day & AAR & t-value & CAAR & t-value \\
\hline-20 & 0.009043 & 0.779020 & 0.009043 & 0.779020 \\
\hline
\end{tabular}

Panel B: Event Study 2 (Market-adjusted model)

\begin{tabular}{|c|c|c|c|c|}
\hline Day & AAR & t-value & CAAR & t-value \\
\hline-20 & 0.01245 & 1.02343 & 0.01245 & 1.02343 \\
\hline
\end{tabular}


Asia-pacific Journal of Convergent Research Interchange

Vol.6, No.9, September 30 (2020), pp.23-33

http://dx.doi.org/10.47116/apjcri.2020.09.03

\begin{tabular}{|c|c|c|c|c|}
\hline-10 & 0.008371 & 1.417938 & 0.035026 & 0.767261 \\
\hline-5 & 0.001393 & 0.211283 & 0.025304 & 0.589023 \\
\hline-4 & 0.002553 & 0.346572 & 0.027856 & 0.621630 \\
\hline-3 & 0.008274 & 1.134393 & 0.036130 & 0.815023 \\
\hline-2 & -0.011995 & -1.232884 & 0.024135 & 0.586147 \\
\hline-1 & 0.013693 & 1.139272 & 0.037828 & 0.872812 \\
\hline 0 & 0.041904 & $2.978448^{* * *}$ & 0.079732 & $1.732537^{*}$ \\
\hline 1 & 0.042769 & $2.60258^{* *}$ & 0.122501 & $2.461769^{* *}$ \\
\hline 2 & 0.008253 & 0.457391 & 0.130755 & $2.393480^{* *}$ \\
\hline 3 & -0.009991 & -0.944853 & 0.120764 & $2.163082^{* *}$ \\
\hline 4 & -0.019897 & -1.665184 & 0.100867 & $1.937468^{*}$ \\
\hline 5 & 0.000877 & 0.092346 & 0.101744 & $1.924187^{* *}$ \\
\hline 10 & 0.004429 & 0.421746 & 0.106395 & $1.848770^{*}$ \\
\hline
\end{tabular}

\begin{tabular}{|c|c|c|c|c|}
\hline-10 & 0.00795 & 1.28512 & 0.05708 & 1.12593 \\
\hline-5 & 0.00275 & 0.38627 & 0.05561 & 1.18214 \\
\hline-4 & 0.00482 & 0.62759 & 0.06043 & 1.21479 \\
\hline-3 & 0.00640 & 0.83815 & 0.06683 & 1.31625 \\
\hline-2 & -0.00964 & -1.08122 & 0.05719 & 1.21526 \\
\hline-1 & 0.01495 & 1.30858 & 0.07214 & 1.57554 \\
\hline 0 & 0.04244 & $3.10569^{* * *}$ & 0.11458 & $2.52300^{* *}$ \\
\hline 1 & 0.04339 & $2.63926^{* *}$ & 0.15796 & $3.41527^{* * *}$ \\
\hline 2 & 0.00815 & 0.45504 & 0.16612 & $3.06807^{* * *}$ \\
\hline 3 & -0.00687 & -0.65093 & 0.15925 & $2.77701^{* * *}$ \\
\hline 4 & -0.01898 & -1.64993 & 0.14027 & $2.64478^{* *}$ \\
\hline 5 & 0.00137 & 0.15501 & 0.14164 & $2.64618^{* *}$ \\
\hline 10 & 0.00849 & 0.78022 & 0.15361 & $2.88979^{* * *}$ \\
\hline \multicolumn{5}{|c}{} \\
\hline
\end{tabular}

As the next step, we investigate which factors are related to stock price responses on M\&A announcements in the E\&M industry. For this analysis, the study adopts the CAAR on the event window of $[-5,5]$ days as the dependent variable. The explanatory variables of growth rate of sales, leverage ratio, $\mathrm{ROE}$, and size of acquiring firms, are firm characteristics examined in prior literature. We are interested in whether these factors have contributions to the announcement window price effects for acquiring companies in the E\&M industry as well.

[Table 4] reports the test results. Unlike prior literature at a market level, no supportive evidence is found that firm characteristics, except leverage, have any influence on CAARs during M\&A announcements. Even the leverage ratio has a negative effect, which is the opposite impact direction of most prior studies.

[Table 4] Firm Characteristics and Stock Response: using CAAR[-5,5]

\begin{tabular}{|c|c|c|c|c|}
\hline & \multicolumn{2}{|c|}{ Panel A: Event Study 1 } & \multicolumn{2}{c|}{ Panel B: Event Study 2 } \\
\hline Variable & Parameter Estimate & t-value & Parameter Estimate & t-value \\
\hline Intercept & 0.0801 & 1.421 & 0.1273 & 0.555 \\
\hline Growth rate of sales & -0.0105 & -0.311 & -0.0082 & -0.234 \\
\hline Leverage & -0.0433 & $-1.942^{*}$ & -0.0424 & $-1.762^{*}$ \\
\hline ROE & -0.1766 & -1.625 & -0.1737 & -1.522 \\
\hline Size & \multicolumn{2}{|c|}{0.0874} & -0.013 & -0.209 \\
\hline R-square & \multicolumn{2}{c}{0.0885} \\
\hline
\end{tabular}

\section{Conclusion}

E\&M firms are experiencing a drastic transformation. In today's fiercely competitive business landscape, M\&As have emerged as an important survival strategy among E\&M firms. This paper analyzed the effect of $M \& A$ announcements in the $E \& M$ industry. Using M\&A events between 2000 and 2019 in the Korean E\&M industry, return movements surrounding the M\&A announcements were identified.

We found positive stock price movements on the day of announcement. During the post- 
announcement period, stock returns exhibited positive values without showing significant return reversals. These empirical findings indicate that M\&A announcements benefit the shareholder wealth of bidding firms. This paper also demonstrates that firm characteristics have different influences on the stock responses in the E\&M industry compared to previous studies.

The results suggest that researchers should be cautious conducting tests and interpreting results when using samples composed of heterogeneous industries. We expect that this study may contribute to the decision-making process of financial market participants, including current and potential shareholders and firms' financial managers, and, furthermore, to the general public for enhancing the understanding of the E\&M industry, which has historically been explored less from financial perspectives.

\section{References}

[1] H. Chung, H. Choi, The effect of Attribute of Smartphone-based Learning of Commercial Educational Purpose on Satisfaction and Recommendation Intention: Focusing on English Education and Learning, International Journal of Computer Science and Information Technology for Education, (2018), Vol.3, No.2, pp.1-8.

[2] J. W. Oak, Educational Needs of Nursing Student in the Development of a Virtual Reality-Based Program for Medication Education, International Journal of IT-based Public Health Management, (2018), Vol.5, No.1, pp.1-6.

[3] S. Park, K. Kim, A Meta Analysis on Robot Learning in early childhood Education in Korea, International Journal of Computer Science and Information Technology for Education, (2016), Vol.1, No.1, pp.43-48.

[4] D. Yoon, J. Kim, Preparation and Direction of Fourth Industry Revolution in the Appraisal Industry, International Journal of Smart Business and Technology, (2019), Vol.7, No.1, pp.31-38.

[5] M. Martynova, L. Renneboog, The Performance of the European Market for Corporate Control: Evidence from the Fifth Takeover Wave, European Financial Management, (2011), Vol.17, No.2, pp.208-259, https://doi.org/10.1111/j.1468-036X.2009.00497.x

[6] K. Craninckx, N. Huyghebaert, Do weakly governed acquirers make intrinsically bad deals? A study on European takeovers, The 62nd Annual Meeting of MFA, (2013), March, USA, Chicago.

[7] M. Mateev, Is the M\&A announcement effect different across Europe? More evidences from continental Europe and the UK, Research in International Business and Finance, (2017), Vol.40, pp.190-216.

[8] J. Danbolt, G. Maciver, Cross Border versus Domestic Acquisitions and the Impact on Shareholder Wealth, Journal of Business Finance and Accounting, (2012), Vol.39, No.7-8, pp.1028-1067.

[9] M. Mateev, K. Andonov, Do cross-border and domestic bidding firms perform differently? New evidence from continental Europe and the UK, Research in International Business and Finance, (2016), Vol.37, pp.327-349. 
[10] M. Isa, S. P. Lee, Method of payment and target status: announcement returns to acquiring firms in the Malaysian market, International Journal of Economics and Finance, (2011), Vol.3, No.3, pp.177-189.

[11] R. Stunda, The market impact of mergers and acquisitions on acquiring firms in the U.S., Journal of Accounting and Taxation, (2014), Vol.6, No.2, pp.30-37.

[12] J. Y. Chae, Y. K. Yoon, A study of consumption characteristics of K-POP in France, Journal of Arts Management and Policy, (2013), No.28, pp.137-166.

[13] B. C. Cho, H. Sim, Sucess Factor Analysis of K-POP and A Study on sustainable Korean Wave - Focus on Smart Media based on Realistic Contents, The Journal of the Korea Contents Association, (2013), Vol.13, No.5, pp.90-102, https://doi.org/10.5392/JKCA.2013.13.05.090

[14] S. H. Kwon, J. Kim, The cultural industry policies of the Korean government and the Korean Wave, International Journal of Cultural Policy, (2014), Vol.20, No.4, pp.422-439.

[15] O. Fedorenko, Korean wave celebrities between global capital and regional nationalisms, Inter-Aisa Cultural Studies, (2017), Vol.18, No.4, pp.498-517.

[16] J. Parc, H. C. Moon, Korean dramas and films: Key factors for their international competitiveness, Asian Journal of Social Science, (2013), Vol.41, No.2, pp.126-149.

[17] S. Yanga, S. Kim, Do cross-border M\&As by Chinese media and entertainment firms create value? Evidence form US-targeted and Korea-targeted deals, 14th International Telecommunications Society Asia-Pacific Regional Conference, (2017), June 24-27; Kyoto, Japan.

[18] J. K. Jha, Effect of cultural differences on performance of merger and acquisition via psychological safety: A Framework, OPUS: HR Journal, (2015), Vol.6, No.2, pp.18-37.

[19] M. Chakraborty, The Wealth Effects of Takeover Announcement for Firms in the Financial Services Sector in India, Journal of Emerging Market Finance, (2010), Vol.9, No.2, pp.199-227. 